\title{
POTENCIAL INVASOR DE DUAS CULTIVARES DE Melinis minutiflora NO CERRADO BRASILEIRO - CARACTERÍSTICAS DE SEMENTES E ESTABELECIMENTO DE PLÂNTULAS ${ }^{1}$
}

\author{
Carlos Romero Martins ${ }^{2}$, John Du Vall $\mathrm{Hay}^{3}$ e Ricardo Carmona ${ }^{4}$
}

\begin{abstract}
RESUMO - A invasão biológica por espécies exóticas é considerada uma das principais ameaças para a conservação da biodiversidade em áreas protegidas. Devido à sua agressividade, Melinis minutiflora P. Beauv. (capim-gordura) é a gramínea que tem causado o maior impacto sobre a flora nativa no Cerrado brasileiro. Este estudo objetivou avaliar características de sementes e de estabelecimento de plântulas que podem afetar o potencial invasor de duas cultivares do Melinis minutiflora em uma área de Cerrado sensu stricto dentro de uma Unidade de Conservação. As avaliações de campo e laboratório mostram que a produção de sementes foi de $192 \mathrm{~kg} / \mathrm{ha}$ (71.946 sementes viáveis $\left./ \mathrm{m}^{2}\right)$ e $171 \mathrm{~kg} / \mathrm{ha}\left(81.690\right.$ sementes viáveis $\left./ \mathrm{m}^{2}\right)$ pelas cultivares Cabelo-de-Negro e Roxo, respectivamente, e as sementes recém-colhidas apresentaram alta viabilidade e alta dormência. No tocante à dinâmica de colonização, o enterrio de sementes reduz a emergência de plântulas, mas não impede a emergência de plântulas até a profundidade de $3 \mathrm{~cm}$, entretanto a partir da profundidade de $4 \mathrm{~cm}$ as plântulas não conseguem emergir. A emergência de plântulas ocorre entre dezembro e março. Fatores adversos como sombreamento, competição intra e interespecífica, baixa fertilidade do solo e estresse hídrico não eliminam totalmente os indivíduos que se estabeleceram no período chuvoso. As cultivares de Melinis minutiflora mostraram comportamento reprodutivo bastante similar, e os fatores estudados ajudaram a explicar parcialmente o sucesso apresentado por essa gramínea em colonizar ambientes naturais no Cerrado brasileiro.
\end{abstract}

Palavras-chave: Melinis minutiflora, capim-gordura e germinação.

\section{INVASION POTENTIAL OF TWO CULTIVARS OF Melinis minutiflora IN THE BRAZILIAN CERRADO - SEED CHARACTERISTICS AND SEEDLING ESTABLISHMENT}

\begin{abstract}
Biological invasion by exotic species is considered one of the main threats to biodiversity conservation in protected areas. Due to its aggressiveness, Melinis minutiflora P. Beauv (molasses grass) is considered as the grass that has caused the highest impact on the native flora of the Brazilian Cerrado. The objective of the present study was to evaluate the invasive potential of two cultivars of Melinis minutiflora. Field and laboratory evaluations showed a seed production of $192 \mathrm{~kg} / \mathrm{ha}$ (71946 viable seeds $\left./ \mathrm{m}^{2}\right)$ and $171 \mathrm{~kg} / \mathrm{ha}(81690$ viable seeds $/ \mathrm{m}^{2}$ ) and $171 \mathrm{~kg} / \mathrm{ha}$ for the cultivars Cabelo-de-Negro and Roxo, respectively. Recently collected seeds presented high viability and dormancy. As for colonization, the burial of seeds up to $3 \mathrm{~cm}$ of depth did not hinder seedling emergence, but the seeds of both cultivars buried at $4 \mathrm{~cm}$ did not emerge. The emergence of seedlings occurred from December to March. However, adverse factors such as shade, inter and intraspecific competition, low soil fertility and water stress did not completely eliminate all of the recently established individuals in the last rainy season. These cultivars of molasses grass showed similar behavior and the factors studied help to partially explain the success of this grass in colonizing natural habitats in the Brazilian Cerrado.
\end{abstract}

Keywords: Germination, molasses grass and seed production.

\footnotetext{
${ }^{1}$ Recebido em 25.09.2007 e aceito para publicação em 29.05.2009.

${ }^{2}$ IBAMA/DILIC/COGEL, Avenida L-4 Norte SAIN. 70800-200 Brasília, DF. E.mail: <carlos.martins@ ibama.gov.br>.

${ }^{3}$ Departamento de Ecologia da Universidade de Brasília (UnB). E-mail: <jhay @ unb.br>.

${ }^{4}$ Faculdade de Agronomia e Medicina Veterinária da UnB. E.mail: <rcarmona@ unb.br>.
} 


\section{INTRODUÇÃO}

Nas últimas décadas, o estabelecimento, naturalização e expansão das espécies invasoras têm sido responsável por grandes mudanças na composição das espécies, na estrutura das comunidades e nas principais funções de vários ecossistemas naturais em diferentes partes do mundo (PIVELLO et al., 1999b; D'ANTONIO e MEYERSON, 2002; PANETTA e TIMMINS, 2004).

As gramíneas de origem africana Andropogon gayanus Kunth, Brachiaria decumbens Stapf. ( = Urochloa decumbens (Stapf) R.D. Webster), Hyparrhenia rufa (Nees) Staf, Melinis minutiflora P. Beauv. e as gramíneas asiáticas Bambusa vulgaris Schrad. ex J.C. Wendl. e Phyllostachys bambusoides Sielbod \& Zucc. foram introduzidas no Brasil acidentalmente ou para fins comerciais e se espalharam por grandes extensões de ambientes naturais e antropizados, deslocando espécies nativas graças à sua agressividade e ao seu grande poder competitivo (PIVELLO et al., 1999a; MARTINS et al., 2004a; FILGUEIRAS, 2005).

Melinis minutiflora (capim-gordura) é uma invasora extremamente agressiva que compete com sucesso com a flora nativa. Nos ambientes invadidos, é capaz de descaracterizar em poucos anos a fisionomia da vegetação original (FILGUEIRAS, 1990). No Cerrado brasileiro, é considerada uma das principais espécies invasoras, e temse tornado grande problema para a conservação da vegetação nativa nas unidades de conservação (FILGUEIRAS, 1990; PIVELLO et al., 1999a; MARTINS et al., 2004a).

De acordo com D'Antonioe Vitousek (1992), a intensa produtividade de Melinis minutiflora que gera grande quantidade de biomassa combustível, especialmente no período seco, pode alterar o regime de fogo das áreas invadidas, facilitando, assim, a ocorrência de grandes incêndios. A presença de resina inflamável nessa espécie também contribui significativamente para grandes incêndios, implicando temperaturas mais elevadas quando comparadas com a temperatura do ar em queimadas na vegetação nativa. Estudos conduzidos por Hoffmann et al. (2004) mostraram que em áreas de transição entre o Cerrado e uma mata de galeria o estabelecimento das espécies arbustivas e arbóreas nativas foi afetado negativamente pela presença dessa gramínea.

O potencial de uma espécie de tornar-se invasora é o resultado da combinação dos atributos da planta, das propriedades ecológicas do ambiente, dos distúrbios naturais ou das práticas de manejo às quais o ambiente é submetido. O conhecimento da biologia de uma espécie invasora é a base para a implementação das estratégias apropriadas para seu manejo (MACINTYRE et al., 1995; BHOWMIK, 1997).

Apesar de representar ameaça para os ecossistemas naturais, principalmente o ecossistema de Cerrado, Melinis minutiflora ainda carece de estudos no Brasil (FREITAS, 1999). No território brasileiro, as cultivares mais conhecidas dessa gramínea são: Roxo, Cabelo-de-Negro, Branco e Francano (BRASIL, 1953), sendo apenas as duas primeiras encontradas no Distrito Federal.

O objetivo deste trabalho foi avaliar características reprodutivas e de estabelecimento que podem afetar o potencial invasor de duas cultivares de Melinis minutiflora encontradas no Parque Nacional de Brasília, Distrito Federal. Essas informações devem ajudar a compreender o sucesso de Melinis minutiflora em colonizar áreas protegidas do Cerrado brasileiro, bem como servir de subsídio para a proposição de métodos mais racionais para o manejo dessa espécie em áreas de proteção ambiental.

\section{MATERIAL E MÉTODOS}

\section{1. Área de estudo}

O estudo foi conduzido no Parque Nacional de Brasília contemplado pelo Decreto $\mathrm{n}^{\circ}$ 241/61 (30.000 ha), situado entre os paralelos $15^{\circ} 34^{\prime}$ e $15^{\circ} 45^{\prime} \mathrm{S}$ e os meridianos $48^{\circ} 05^{\prime}$ e $48^{\circ} 53^{\prime}$ W. Recentemente, a Lei no 11.282 , de 8 de março de 2006, ao redefinir a sua poligonal, acrescentou cerca de 11.000 ha aos limites noroeste dessa Unidade de Conservação. O parque apresenta altitude entre 1.070 e $1.200 \mathrm{~m}$, em que predominam os Latossolos Vermelho-Escuros distróficos, dando suporte ao Cerrado denso. Outras formas de vegetação como campos e matas de galeria aparecem sobre litossolos e solos hidromórficos, respectivamente. O clima é tropical (KÖppen Aw), e a precipitação média anual é da ordem de $1.600 \mathrm{~mm}$, com uma concentração das chuvas em um período de cinco a seis meses (novembro a abril) (FUNATURA/IBAMA, 1998).

A área experimental insere-se na Zona de Uso Especial, confronta-se com a Zona de Uso Intensivo do Parque Nacional e dista cerca de $400 \mathrm{~m}$ da sede administrativa. A vegetação é classificada como Cerrado 
sensu stricto, subtipo Ralo, de acordo com Ribeiro e Walter (1998). A biomassa do estrato rasteiro gira em torno de 8,5 t/ha, e Melinis minutiflora representa $55 \%$ desse total (MARTINS, 2006). Segundo Coelho (2002), a última queimada registrada na área de estudo ocorreu no ano de 1986. Melinis minutiflora está presente na área do parque antes da sua criação, e essa gramínea é encontrada em cerca de 4.100 ha dessa unidade de conservação (MARTINS et al., 2004b; MARTINS, 2006).

\subsection{Parâmetros estudados}

\section{Produção e características das sementes}

Neste trabalho, as unidades de dispersão de Melinis minutiflora (espiguetas cheias e vazias) das cultivares Roxo e Cabelo-de-Negro são referidas como sementes (ALLRED, 1982). As avaliações de campo foram realizadas nos anos de 2001, 2002 e 2003, e em cada ano 45 inflorescências de cada cultivar foram coletadas manual e aleatoriamente, no mês de junho. As inflorescências foram secas à sombra em laboratório, pelo período de dois meses. O material foi trilhado e limpo manualmente e as sementes, acondicionadas em sacos de papel permeável.

As avaliações das características das sementes foram feitas no Laboratório de Sementes da Faculdade de Agronomia e Medicina Veterinária da Universidade de Brasília. A porcentagem em número de sementes cheias (contendo cariópse) foi determinada mediante separação e pesagem das frações espiguetas cheias e vazias. As sementes cheias foram separadas das vazias mediante uso de assoprador (marca General Seed Blower) por $3 \mathrm{~min}$, previamente regulado na abertura adequada para cada cultivar. Após a separação, contou-se o número de sementes cheias e vazias, e, em seguida, determinou-se à massa dessas frações. Devido à presença de aristas nas sementes da cultivar Roxo, em cada operação no assoprador o peso máximo de cada porção de sementes não excedeu a $0,10 \mathrm{~g}$ para evitar o entrelaçamento entre as sementes.

Os testes de germinação, conduzidos no mês de outubro, foram realizados em câmaras de germinação tanto nas temperaturas alternadas de $20^{\circ}-30^{\circ} \mathrm{C} \mathrm{(16/}$ $8 \mathrm{~h}$ ) com luz florescente branca em nitrato de potássio a $0,5 \%$, quanto na temperatura constante de $25^{\circ} \mathrm{C}$ no escuro e em água. A temperatura alternada foi usada para estimar a viabilidade, enquanto a constante, para a dormência das sementes (CARMONA et al., 1999). Foram utilizadas placas de Petri de poliestireno transparente forradas com duas folhas de papelfiltro umedecidas com nitrato de potássio ou água, conforme o teste.

As avaliações de germinação foram realizadas diariamente nos testes em presença de luz, a fim de monitorar a evolução do processo germinativo, reumedecendo o substrato com água destilada sempre que necessário. Os testes na ausência de luz foram conduzidos envolvendo-se cada placa de Petri com duas folhas de papel-alumínio. Nesse caso, as placas foram seladas com fita adesiva para evitar o ressecamento do substrato.

Todos os testes de germinação constaram de quatro repetições de 100 sementes cheias em delineamento inteiramente casualizado (BRASIL, 1992). Os testes no escuro foram avaliados uma única vez, ao final das avaliações em presença de luz. Considerou-se germinada a semente que emitiu pelo menos $2 \mathrm{~mm}$ de radícula e, ou, coleóptile.

\section{Efeito da profundidade de enterrio na emergência de plântulas}

Para essa avaliação, utilizaram-se recipientes plásticos de $250 \mathrm{~mL}$, e o substrato usado foi solo coletado na área experimental, a uma profundidade de $15 \mathrm{~cm}$ (previamente esterilizado a $100^{\circ} \mathrm{C}$ por $48 \mathrm{~h}$ ). De acordo com Mohler e Golford (1997), a maioria das sementes das espécies invasoras concentra-se na superfície do solo e em pequenas profundidades, de onde ocorre a emergência das plântulas. Dessa forma, as sementes foram posicionadas nas profundidades de $0,1,2,3$ e $4 \mathrm{~cm}$. Os tratamentos constaram de quatro repetições de 50 sementes cheias.

Os ensaios de emergência das plântulas foram conduzidos na presença de luz com temperaturas alternadas entre $20^{\circ}-30^{\circ} \mathrm{C}(16-8 \mathrm{~h})$. Para evitar o efeito da incidência lateral de luz no processo de germinação das sementes, os recipientes foram envoltos com papelalumínio. Para manter o solo sempre úmido, os recipientes foram furados na base e, em seguida, distribuídos em bandejas plásticas com dimensões de $28 \mathrm{~cm}$ x $18 \mathrm{~cm}$ x $8 \mathrm{~cm}$ contendo uma lâmina de $2 \mathrm{~cm}$ de água destilada. A emergência das plântulas foi avaliada diariamente pelo período de três meses, e, após o registro, as plântulas foram descartadas.

R. Árvore, Viçosa-MG, v.33, n.4, p.713-722, 2009 


\section{Estabelecimento de plântulas}

O estabelecimento espontâneo de plântulas de Melinis minutiflora oriundas de sementes encontradas no banco de sementes na área experimental foi avaliado entre dezembro de 2003 e dezembro de 2004, em quatro parcelas de $10 \mathrm{~m}$ x $10 \mathrm{~m}$ demarcadas aleatoriamente. Em cada parcela, estabeleceram-se aleatoriamente quatro quadrados fixos de $25 \mathrm{~cm}$ x $25 \mathrm{~cm}$, sem a remoção da vegetação natural. O número de plântulas foi registrado em dezembro/03, janeiro/04, fevereiro/04, março/04, abril/ 04 e em dezembro/04.

\section{Análises estatísticas}

A análise de variância de um critério (estatística F) foi usada para verificar a presença de diferenças estatísticas entre a massa média das sementes cheias e a viabilidade e dormência das sementes cheias. A análise de variância não paramétrica de Kruskal-Wallis (estatística H) foi usada para verificar a presença de diferenças estatísticas entre a porcentagem de sementes cheias entre anos e o efeito de profundidade. Na constatação de diferenças significativas, o teste a posteriori de Tukey (valor de $\alpha=0,05$ ) foi usado para determinar quais médias eram diferentes. O teste não paramétrico de Mann-Whitney (estatística U) foi usado para verificar a presença de diferenças estatísticas entre as cultivares quanto à emergência após o enterrio em profundidades diferentes. As probabilidades estão apresentadas de forma exata ou $\operatorname{com} \alpha<0,01$. O programa utilizado foi Statistix 8 (ANALYTICAL SOFTWARE, 2003).

\section{RESULTADOS E DISCUSSÃO}

O número médio de sementes cheias por inflorescência foi de $450 \pm 108$ para a cultivar Roxo e de $300 \pm 135$ para a cultivar Cabelo-de-Negro. Esses resultados corroboram as observações de Filgueiras (1990), que relatou que o grande potencial invasor de Melinis minutiflora se deve, em parte, à sua grande produção de sementes (Tabela 1).

A percentagem média de sementes cheias, nos três anos, na cultivar Roxo foi de $29 \%$, enquanto na cultivar Cabelo-de-Negro foi de $30 \%$ (Tabela 1). A comparação entre anos de cada cultivar mostrou diferença $(\mathrm{H}=22,17 ; \mathrm{p}<0,01)$, e a cultivar Roxo apresentou maior porcentagem de sementes cheias no ano de 2001, enquanto na cultivar Cabelo-de-Negro $(H=19,35$, $\mathrm{p}<0,01)$ apresentou a maior porcentagem de sementes cheias em 2003.

Os valores de porcentagem de sementes cheias estão em conformidade com os valores observados em Melinis minutiflora no Brasil por outros autores, que pode variar de 25 a 40\% (BRASIL, 1953; ROCHA et al., 1965; FREITAS e PIVELLO, 2005). Esse comportamento mostra que essa gramínea apresenta alta taxa de esterilidade natural de sementes. Segundo Maschieto (1981) e Carmona et al. (1999), vários fatores podem condicionar a ocorrência de esterilidade de sementes em gramíneas, incluindo aspectos genéticos e fatores ambientais. Entretanto, a causa desse fenômeno não está devidamente elucidada, sendo, portanto, necessárias mais pesquisas nessa área.

A cultivar Roxo apresentou peso médio de 1.000 sementes cheias de $0,11 \mathrm{~g}$, enquanto na cultivar Cabelode-Negro esse peso foi de $0,10 \mathrm{~g}$ (Tabela 2). Não houve diferença significativa na massa das sementes cheias da cultivar Roxo entre anos $\left(\mathrm{F}_{2,132}=1,53 ; \mathrm{p}=0,22\right)$, mas com a cultivar Cabelo-de-Negro houve diferença significativa $\left(F_{2,132}=5,31 ; p=0,006\right)$, e as sementes coletadas no ano de 2002 diferiram das colhidas no ano de 2003.

Tabela 1 - Características das sementes das cultivares Roxo e Cabelo-de-Negro de Melinis minutiflora (capim-gordura), coletadas no Parque Nacional de Brasília, Distrito Federal, nos anos de 2001, 2002 e 2003

Table 1 - Characteristics of the seeds of the cultivars Roxo and Cabelo-de-Negro of Melinis minutiflora (molasses grass), collected in the National Park of Brasília, Distrito Federal, in 2001, 2002 and 2003

\begin{tabular}{|c|c|c|c|}
\hline Cultivares/características & Período de avaliação & Cultivar Roxo & Cultivar Cabelo-de-Negro \\
\hline Quantidade de & 2001 & 498 & 211 \\
\hline sementes cheias & 2002 & 325 & 234 \\
\hline \multirow[t]{2}{*}{ por inflorescência } & 2003 & 526 & 456 \\
\hline & Média & $450 \pm 108$ & $300 \pm 135$ \\
\hline Percentagem & 2001 & $35 \pm 9$ & $25 \pm 17$ \\
\hline de sementes & 2002 & $23 \pm 10$ & $28 \pm 10$ \\
\hline \multirow[t]{2}{*}{ cheias } & 2003 & $28 \pm 14$ & $37 \pm 10$ \\
\hline & Média & $29 \pm 11$ & $30 \pm 12$ \\
\hline
\end{tabular}

R. Árvore, Viçosa-MG, v.33, n.4, p.713-722, 2009 
Tabela 2 - Produção de sementes (kg/ha) das cultivares Roxo e Cabelo-de-Negro de Melinis minutiflora (capim-gordura), no Parque Nacional de Brasília, Distrito Federal, nos anos de 2001, 2002 e 2003

Table 2 - Seed production ( $k g / h a)$ of the cultivars Roxo and Cabelo-de-Negro of Melinis minutiflora (molasses grass) in the National Park of Brasília, Distrito Federal, in 2001, 2002 and 2003

\begin{tabular}{cccc}
\hline Cultivares/produção de sementes & Período de avaliação & Cultivar Roxo & Cultivar Cabelo-de-Negro \\
\hline Massa 100 & 2001 & $0,120 \pm 0,002$ & $0,100 \pm 0,002$ \\
sementes & 2002 & $0,110 \pm 0,002$ & $0,090 \pm 0,002$ \\
cheias (g) & 2003 & $0,110 \pm 0,001$ & $0,110 \pm 0,001$ \\
\hline & Média & $0,113 \pm 0,002$ & $0,100 \pm 0,002$ \\
\hline Número de & 2001 & 79680 & 57392 \\
sementes & 2002 & 52000 & 63648 \\
cheias/m & 2003 & 84160 & 124032 \\
\hline Produção de & Média & 71946 & 81690 \\
sementes* & 2001 & 214 & 160 \\
(kg/ha) & 2002 & 161 & 139 \\
\hline & 2003 & 200 & 214 \\
\hline A & Média & 191,7 & 171 \\
\hline
\end{tabular}

A produção de sementes (cheias + vazias) foi calculada com base no número de 160 panículas $/ \mathrm{m}^{2}$ para cultivar Roxo e 272 panículas/m² para cultivar Cabelo-de-Negro (C.R. MARTINS, dados não publicados).

Em razão de características das sementes como presença de aristas, tamanho reduzido (1,5 a 2,5 mm) e baixo peso relativamente a outras espécies de gramíneas nativas da região do Cerrado brasileiro (ARONIVICH eROCHA, 1985; SKERMAN RIVERS, 1992; CARMONA et al., 1999), essa gramínea apresenta grande potencial dispersor. Ressalta-se que, das cultivares estudadas, as sementes da cultivar Roxo apresentam aristas alongadas (6 a $12 \mathrm{~mm}$ ), enquanto as sementes da cultivar Cabelo-de-Negro são desprovidas de aristas.

A produção de sementes cheias nas áreas onde Melinis minutiflora apresenta alto índice de cobertura (> 95\%) foi de cerca de 72.000 sementes $/ \mathrm{m}^{2}$ da cultivar Roxo e de 81.500 sementes $/ \mathrm{m}^{2}$ da cultivar Cabelo-deNegro (Tabela 2). No que concerne à produção total de sementes, estima-se uma produção em torno de $192 \mathrm{~kg} / \mathrm{ha}$ de sementes (cheias + vazias) da cultivar Roxo, enquanto a cultivar Cabelo-de-Negro alcança $171 \mathrm{~kg} /$ ha sementes (cheias + vazias) (Tabela 2). Os resultados indicam um excelente desempenho de ambas as cultivares, pois se trata de uma colonização espontânea quando comparado com áreas de pastagens cultivadas, onde a produção média varia de $200 \mathrm{~kg} /$ ha (MITIDIERI, 1983) a 280 kg/ha (BOGDAN, 1977; SKERMAN e RIVERS, 1992).

As sementes recém-colhidas de ambas as cultivares de Melinis minutiflora apresentaram alta viabilidade e alta dormência (Tabela 3). Com as duas cultivares não houve diferença na viabilidade entre anos, mas a dormência na cultivar Cabelo-de-Negro apresentou diferença significativa $\left(\mathrm{F}_{2,9}=9,75\right.$; $\mathrm{p}=0,006)$, entre os anos de 2001 e 2003. Toda a comparação entre a viabilidade e dormência da mesma cultivar no mesmo ano foi significativa, exceto na cultivar Cabelo-de-Negro em 2003 (Tabela 3). Entretanto, as comparações entre cultivares quanto à viabilidade ou dormência foram não significativas, exceto para dormência no ano de 2003.

Tabela 3 - Viabilidade e dormência de sementes das cultivares Roxo e Cabelo-de-Negro do Melinis minutiflora (capim-gordura), colhidas no Parque Nacional de Brasília, Distrito Federal, nos anos de 2001, 2002 e 2003

Table 3 - Viability and dormency of seeds of the cultivars Roxo and Cabelo-de-Negro of Melinis minutiflora (molasses grass) collected in the National Park of Brasilia, Distrito Federal, in 2001, 2002 and 2003

\begin{tabular}{lcccccc}
\hline Avaliações & \multicolumn{3}{c}{ Cultivar Roxo } & & \multicolumn{3}{c}{ Cultivar Cabelo-de-Negro } \\
\cline { 2 - 4 } \cline { 5 - 7 } & 2001 & 2002 & 2003 & & 2001 & 2002 \\
\hline Viabilidade (\%) & $94 \mathrm{a}$ & $89 \mathrm{a}$ & $93 \mathrm{a}$ & & $97 \mathrm{a}$ & $91 \mathrm{a}$ \\
Dormência (\%) & $67 \mathrm{~b}$ & $64 \mathrm{~b}$ & $61 \mathrm{~b}$ & & $66 \mathrm{~b}$ & $97 \mathrm{a}$ \\
\hline
\end{tabular}

Viabilidade (estimada pelo teste de germinação na presença de luz, nitrato de potássio e temperaturas alternadas de $20^{\circ}-30^{\circ} \mathrm{C} 16$ $8 \mathrm{~h}$ ) e dormência (estimada pela diferença da viabilidade e germinação no ambiente escuro, com temperatura constante de $25^{\circ} \mathrm{C}$ ) Em cada cultivar, médias seguidas pela mesma letra na linha não diferem significativamente a 5\% de probabilidade, pelo teste a posteriori de Tukey. 
Freitas e Pivello (2005) relataram que as sementes de Melinis minutiflora apresentam ligeira dormência até um mês depois da colheita, o que difere do resultado encontrado neste estudo, pois, nas condições estudadas, as sementes das cultivares estudadas após quatro meses de sua coleta, de forma geral, apresentaram elevado nível de dormência primária (ou inata). Aliado a isso, essa gramínea se caracteriza por produzir grande quantidade de sementes com elevado poder germinativo. Esse comportamento reforça a hipótese de que a elevada produção de sementes viáveis e dormentes contribui para a formação de expressivos bancos de sementes no solo.

Os ensaios realizados em condições de laboratório mostraram que a emergência de plântulas decresce com o aumento da profundidade de enterrio das sementes (Figura 1). Em ambas as cultivares, os valores encontrados diferem entre as profundidades estudadas (Roxo $\mathrm{H}=16,85 ; \mathrm{p}<0,0001$ e Cabelode-Negro $\mathrm{H}=17,72 ; \mathrm{p}<0,0001)$. As plântulas emergem desde a superfície até a profundidade de $3 \mathrm{~cm}$. Em profundidades superiores a $3 \mathrm{~cm}$, não ocorreu emergência.

A máxima emergência de plântulas foi registrada na superfície do solo (cultivar Roxo $=83 \%$ e cultivar Cabelo-de-Negro $=85 \%$ ), reduzindo gradativamente com o aumento na profundidade de semeadura. Comparando o comportamento entre as duas cultivares, pode-se observar que não existe diferença nas profundidades $0 \mathrm{~cm}(\mathrm{U}=9,0 ; \mathrm{p}=0,857), 2 \mathrm{~cm}$ $(\mathrm{U}=6,4 ; \mathrm{p}=0,0571)$ e $3 \mathrm{~cm}(\mathrm{U}=4,9 ; \mathrm{p}=0,714)$ (Figura 1). Por sua vez, na profundidade de $1 \mathrm{~cm}$ a cultivar Cabelo-de-Negro apresentou praticamente o dobro da emergência de plântulas que a cultivar Roxo, e os valores diferiram entre as cultivares $(U=6,5$; $\mathrm{p}=0,0286)$. Esse comportamento mostra o grande potencial de estabelecimento de plântulas de Melinis minutiflora oriundas de sementes na (ou próximas à) superfície do solo. Em condições naturais, as sementes dispersas devem concentrar-se mais próximo da superfície do solo. Nessa posição, se as condições climáticas e edáficas forem favoráveis, a emergência das plântulas de Melinis minutiflora deve ser mais rápida e intensa, favorecendo o rápido estabelecimento de novas plantas.

De acordo com Borghetti e Ferreira (2004), a germinação rápida e uniforme é característica de espécies cuja estratégia é se estabelecer no ambiente o mais rápido possível ou quando oportuno, aproveitando condições ambientais favoráveis ao desenvolvimento do novo indivíduo. Essa situação pode ser criada, por exemplo, com a formação de clareiras ou ocorrência de chuvas. Em contrapartida, a germinação rápida pode ser imprópria ou nãoestratégica ao estabelecimento de uma espécie, por exemplo germinar em resposta à chuva errática e isolada durante a estação seca, e, nesse caso, as sementes germinadas poderiam perecer na continuidade da seca.

O tempo necessário para iniciar o processo de emergência das plântulas foi semelhante nas profundidades de 0 e $1 \mathrm{~cm}$ em ambas as cultivares. Nas profundidades de 2 e $3 \mathrm{~cm}$, a cultivar Cabelo-deNegro apresentou atraso de um dia quando comparado com a cultivar Roxo (Tabela 4). Segundo Mohler e Golford (1997), na maioria das espécies invasoras a profundidade ótima para a emergência de plântulas é menor que 2 $\mathrm{cm}$, contudo o limite máximo de profundidade em que a emergência pode ocorrer não ultrapassa $6 \mathrm{~cm}$.

Há certa dificuldade em comparar estudos sobre a emergência das espécies em diferentes profundidades devido à diferença na dormência das sementes, às condições particulares de temperatura e umidade e, sobretudo, às diferenças entre as características dos solos usados (BENVENUTTI et al., 2001). Os resultados deste estudo são consistentes com os de outros trabalhos (CARDINAe SPARROW, 1996; MOHLER e GOLFORD, 1997), em que a inibição da emergência de plântulas aumenta proporcionalmente com a elevação da profundidade de enterrio das sementes.

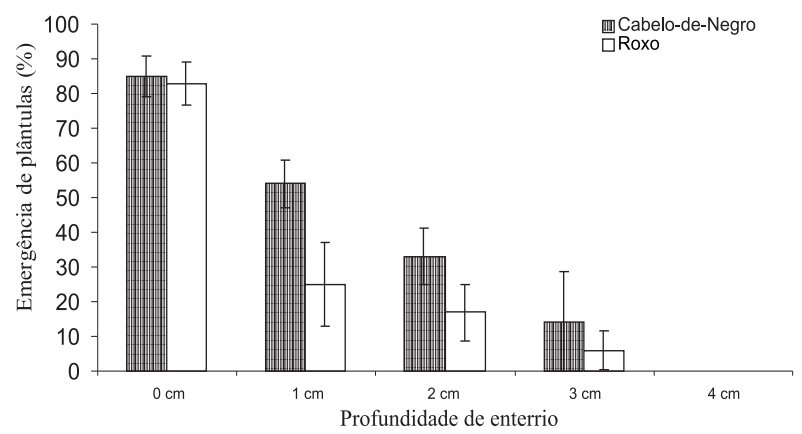

Figura 1 - Emergência de plântulas de Melinis minutiflora (capim-gordura) das cultivares Cabelo-de-Negro e Roxo nas diferentes profundidades de enterrio de suas sementes, coletadas no ano de 2003, no Parque Nacional de Brasília, Distrito Federal.

Figure 1 -Seedling emergence for the cultivars Cabelo-deNegro and Roxo of Melinis minutiflora (molasses grass) planted at different depths, collected in 2003 in the National Park of Brasília, Distrito Federal Federal. 
Tabela 4 - Tempo necessário para iniciar o processo de emergência das plântulas (dias) em sementes de Melinis minutiflora (capim-gordura) enterradas em diferentes profundidades e coletadas no ano de 2003, no Parque Nacional de Brasília, Distrito Federal

Table 4-Length of time to start of emergence of seedlings (days) for seeds of Melinis minutiflora (molasses grass) planted at different depths and collected in 2003 in the National Park of Brasilia, Distrito Federal

\begin{tabular}{|c|c|c|}
\hline Profundidade de enterrio $(\mathrm{cm}) /$ emergência plântulas & Cultivar Roxo & Cultivar Cabelo-de-Negro \\
\hline $\begin{array}{l}0 \\
\end{array}$ & 4 & 4 \\
\hline 1 & 5 & 5 \\
\hline 2 & 7 & 8 \\
\hline 3 & 7 & 8 \\
\hline 4 & - & - \\
\hline
\end{tabular}

O aumento da profundidade no enterrio das sementes pode dificultar a emergência das plântulas ou induzir a dormência das sementes. Contudo, a falta de luz, a temperatura, o conteúdo de água e os diferentes graus de compactação do solo são fatores limitantes à germinação das sementes em diferentes profundidades no solo (BENVENUTTI et al., 2001).

No campo, o fluxo inicial de emergência das plântulas de Melinis minutiflora ocorreu no mês de dezembro de 2003, dois meses após o começo do período chuvoso. O processo de estabelecimento das plântulas se estendeu até março de 2004. No primeiro levantamento, registrouse um recrutamento de 439 indivíduos $/ \mathrm{m}^{2}$, e, ao longo dos meses subsequentes, esse valor decresceu próximo do mês de abril de 2004, final do período chuvoso, a 36 indivíduos $/ \mathrm{m}^{2}$. No mês de dezembro de 2004, 12 meses após o estabelecimento inicial dessa gramínea foram observados 29 indivíduos $/ \mathrm{m}^{2}$, o que representa taxa de sobrevivência de 6,6\% em relação ao número de indivíduos presentes no início da avaliação (Figura 2).

Informações sobre o estabelecimento de plântulas de Melinis minutiflora em ambientes naturais são inexistentes no país. No entanto, para formação de pastagens a densidade de semeio depende muito da qualidade das sementes e, nesse contexto, recomendase o uso de 1,5 a 6,0 kg de sementes/ha, o que deve alcançar um número médio de 300 sementes viáveis/ m² (MIDITIERI, 1983; SKERMANe RIVERS, 1992). Tendo em vista que o percentual de germinação das sementes dessa gramínea pode variar de 80 a 95\% (ANDRADE, 1983; MARTINS etal., 2004b; FREITAS e PIVELLO, 2005), nesse caso pode-se especular que, na fase inicial do estabelecimento, sejam encontrados entre 240 e 285 indivíduos $/ \mathrm{m}^{2}$. Por sua vez, Bogdan (1977) relatou que em condições ideais dificilmente a sobrevivência das plântulas dessa gramínea ultrapassa $10 \%$. Assim, os resultados mostram que o desempenho alcançado por
Melinis minutiflora no Cerrado nativo foi semelhante ao encontrado em áreas utilizadas para implantação de pastagens.

No que tange ao desenvolvimento de Melinis minutiflora, observou-se que no mês de dezembro de 2004 as plântulas alcançaram altura média de $2,7 \mathrm{~cm}( \pm 0,7 \mathrm{~cm})$, o que refletiu numa produção de matéria seca de $3,5 \mathrm{~kg}$ / ha. De acordo com Carvalho e Cruz Filho (1985), estudo conduzido em Coronel Pacheco, MG, indicou que, após 12 meses do estabelecimento dessa gramínea em áreas adubadas para renovação de pastagens e submetidas a diferentes métodos de preparo do solo (sem preparo, covas, sulcos e faixas), a produção de matéria seca ( $\mathrm{kg} / \mathrm{ha}$ ) alcançou 2.738, 2.772, 1.714 e 1.088 , respectivamente.

Diante do exposto, o desempenho registrado por Melinis minutiflora pode ser um resultado direto da biomassa presente na área, pois, segundo Carvalho e Cruz Filho (1985), a competição pela vegetação é considerada um dos fatores mais importantes que afetam o crescimento e sobrevivência das plântulas oriundas das sementes posicionadas na superfície do solo.

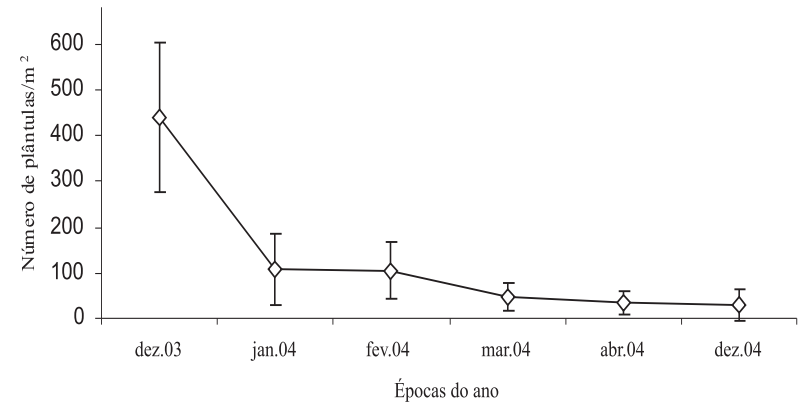

Figura 2 - Estabelecimento de plântulas de Melinis minutiflora (capim-gordura) entre o mês de dezembro de 2003 e dezembro de 2004, no Cerrado nativo, Parque Nacional de Brasília, Distrito Federal.

Figure 2 - Establishment of seedlings of Melinis minutiflora (molasses grass) between December 2003 and December 2004, in a natural Cerrado of the National Park of Brasilia, Distrito Federal.

R. Árvore, Viçosa-MG, v.33, n.4, p.713-722, 2009 
Apesar de essa gramínea estar adaptada a solos ácidos e de baixa fertilidade do Brasil Central, o seu crescimento pode ser prejudicado pela deficiência de alguns elementos essenciais como o fósforo e o nitrogênio, que são de grande importância para o crescimento, tanto na fase de estabelecimento quanto na fase de produção (CARVALHO et al., 1985; CARVALHO et al., 1988). Investigações conduzidas por Martins et al. (2004) sinalizaram que o solo da área experimental se caracteriza por apresentar alta acidez e baixa fertilidade natural $(\mathrm{pH}=5,40 \mathrm{me} / 100 \mathrm{cc}$, $\mathrm{Ca}+\mathrm{Mg}=0,72 \mathrm{mg} / \mathrm{l}, \mathrm{P}=0,27 \mathrm{mg} / \mathrm{l}, \mathrm{K}=39,75 \mathrm{mg} / \mathrm{l} \mathrm{e}$ M.O. $=3,73 \%)$.

Avaliações conduzidas por Hughes e Vitousek (1993) mostraram que no Havaí a densa camada de folhas e ramos formados por Melinis minutiflora funciona como barreira que, além de dificultar a chegada das sementes das espécies nativas ao solo, dificulta a sua germinação e o recrutamento das plântulas. Por sua vez, D'Antonio et al. (2001) relataram que, em áreas não queimadas no Havaí, a falta de luz e o estresse hídrico foram responsáveis pela morte de todas as plântulas de Melinis minutiflora após cinco meses do seu estabelecimento. Esse resultado difere do constatado neste estudo, em que as condições adversas encontradas por essa gramínea não foram suficientes para impedir o seu estabelecimento, o que tem contribuído para sua manutenção e perpetuação no Parque Nacional de Brasília.

Nesse caso, com os resultados obtidos foi possível inferir que o comportamento registrado pelas plântulas de Melinis minutiflora pode ser decorrente dos seguintes fatores: sombreamento resultante da densa camada do substrato rasteiro; competição intra e interespecífica; baixa fertilidade do solo; veranicos que ocorreram ao longo do período chuvoso e, principalmente, devido ao longo período de estiagem registrado entre os meses de junho e setembro de 2004, quando foi registrado apenas $0,5 \mathrm{~mm} /$ chuva no mês de julho (dados cedidos pelo Instituto Nacional de Meteorologia - INMET).

O estudo realizado mostrou que as cultivares de Melinis minutiflora avaliadas apresentam desempenho bastante similar, e os fatores investigados ajudam a explicar parcialmente o grande sucesso dessa gramínea em colonizar os ambientes naturais do Centro-Oeste brasileiro.

R. Árvore, Viçosa-MG, v.33, n.4, p.713-722, 2009

\section{CONCLUSÕES}

As cultivares Roxo e Cabelo-de-Negro de Melinis minutiflora apresentam comportamento reprodutivo bastante similar, e o seu elevado potencial invasor pode ser explicado, em parte:

- pela elevada produção de sementes em infestações naturais, pela elevada ocorrência de dormência inata nas suas sementes, pela emergência de plântulas preferencialmente a partir da superfície ou de pequenas profundidades no solo e pela capacidade de estabelecimento em ambientes adversos, o que tem contribuído para a manutenção e expansão de sua população no Cerrado brasileiro.

\section{AGRADECIMENTOS}

Ao Instituto Chico de Mendes de Conservação da Biodiversidade e ao Parque Nacional de Brasília, pela autorização para realizar este trabalho; à Monsanto do Brasil, WWF/Brasil (Código BRZ NT 614/2002); e The Nature Conservancy Brasil (Doação No. 020/ 03), pelo imprescindível apoio.

\section{REFERÊNCIAS}

ALLRED, K. W. Describing the grass inflorescence. Journal of Range Management, v.35, n.5, p.672-675, 1982.

ANALYTICAL SOFTWARE. Statistix 8.0 Analytical software. Tallahassee: 2003. 396p.

ANDRADE, R. V. Épocas de colheita, produção e qualidades de sementes de capim-gordura. Revista Brasileira de Sementes, v.5, n.2, p.9-22, 1983.

ARONOVICH, S.; ROCHA, G. L. Gramíneas e leguminosas forrageiras de importância no Brasil Central Pecuário. Informe Agropecuário, v.11, n.132, p.3-13, 1985.

BENVENUTTI, S.; MACCHIA, M.; MIELE, S. Quantitative analysis of emergence of seedlings from buried weed seeds with increasing soil depth. Weed Science, v.49, p.528-535, 2001.

BHOWMIK, P. C. Weed biology: importance to weed management. Weed Science, v.45, p.349-356, 1977. 
BOGDAN, A. V. Tropical pasture and folder plants. New Yotk: Longman, 1977. 475p.

BORGHETTI, F.; FERREIRA, A. G. Interpretação de resultados de germinação. In: FERREIRA, A.G.; BORGHETTI, F. (Orgs.). Germinação: do básico ao aplicado. Porto Alegre: Artmed, 2004. p.209-222.

BRASIL - Ministério da Agricultura. Seção de Agrostologia e Alimentação dos Animais. O capim-gordura. Rio de Janeiro: 1953. 25p. (Publicação, 6).

BRASIL. Ministério da Agricultura e Reforma Agrária. Secretaria Nacional de Defesa Agropecuária. Departamento Nacional de Defesa Vegetal. Coordenação de Laboratório Vegetal. Regras para análise de sementes. Brasília: 1992.365p.

CARDINA, J.; SPARROW, D. H.; MCCOY, E. L. Spatial relationships between seedbank and seedling populations of Common Lambsquarters (Chenopodium album) and annual grasses. Weed Science, v.44, p.298-308, 1996.

CARMONA, R.; MARTINS, C. R.; FÁVERO, A. P. Características de sementes de gramíneas nativas do cerrado. Pesquisa Agropecuária Brasileira, v.34, p.1067-1074, 1999.

CARVALHO, M. M. et al. Fatores nutricionais limitantes ao crescimento de forrageiras tropicais em dois solos da Zona da Mata, MG. 1. Latossolo Vermelho-Amarelo. Pesquisa Agropecuária Brasileira, v.20, n.5, p.519-528, 1985.

CARVALHO, M. M.; CRUZ FILHO, A. B. Estabelecimento de pastagens. Coronel Pacheco, MG: Embrapa-CNPGL, 1985. 46p. (Circular Técnica, 26).

CARVALHO, M. M.; BOTREL, M. A.; MARTINS, C. E. Recuperando pastagens em áreas de morro e em solos ácidos. Balde Branco, n.279, p.22-24, 1988.

COELHO, H. A. Histórico de regime de fogo do Parque Nacional de Brasília. Brasília: Departamento de Engenharia Florestal, Universidade de Brasília, 2002. 43p. (Monografia de Final de Curso).
D’ANTONIO, C. M.; VITOUEK, P. M. Biological invasions by exotics grasses, the grass/fire, and goal change. Annual Review of Ecology and Systematic, v.23, p.63-87, 1992.

D'ANTONIO, C. M.; HUGHES, R. F.; VITOUSEK, P. M. Factors influencing dynamics of two invasive $\mathrm{C}_{4}$ grasses in seasonally dry Hawaiian Woodlands. Ecology, v.82, n.1, p.89-104, 2001.

D’ANTONIO, C. M.; MEYERSON, L. A. Exotic plant species as problems and solutions in ecological restoration: a synthesis. Restoration Ecology, v.10, n.4, p.703-713, 2002.

FILGUEIRAS, T. S. Africanas no Brasil. Gramíneas introduzidas da África. Cadernos de Geociências, v.5, p.57-63, 1990.

FILGUEIRAS, T. S. Asiáticas no Brasil: gramíneas (Poaceae) introduzidas da Ásia. Eugeniana v.28, p.3-18, 2005.

FREITAS, G. K. Invasão biológica do capim-gordura (Melinis minutiflora Beauv) em um fragmento de cerrado (A.R.I.E Cerrado Pé-de-Gigante, Santa Rita do Passa Quatro). 1999. 147f. Dissertação (Mestrado em Ecologia) Universidade de São Paulo, São Paulo, 1999.

FREITAS, G. K.; PIVELlo, V. R. A ameaça das gramíneas exóticas à biodiversidade. In: PIVELLO, V.R.; VARANDA,E.M. (Orgs.). O cerrado Pé-de-Gigante: ecologia e conservação Parque Estadual de Vassununga. São Paulo: SMA, 2005. p.283-296.

FUnAtura/IBAMA. Plano de Manejo do Parque Nacional de Brasília. Brasília: 1998. v.1.

HOFFMANN, W. A. et al. Impact of the invasive alien grass Melinis minutiflora at the savannaforest ecotone in the Brazilian Cerrado.

Diversity and Distributions, v.10, n.1, p.99-103, 2004.

HUGHES, F.; VITOUSEK, P. M. Barriers to shrub establishment following fire in the seasonal submontane zone of Hawaii. Oecologia, v.93, n.4, p.557-563, 1993.

R. Árvore, Viçosa-MG, v.33, n.4, p.713-722, 2009 
MACINTYRE, S.; LAVOREL, S.; TREMONT, R. M. Plant life-history attributes: their relationship to disturbance response in herbaceous vegetation. Journal of Ecology, v.83, n.1, p.31-44, 1995.

MARTINS, C. R.; LEITE, L. L.; HARIDASAN, M. Capim-gordura (Melinis minutiflora P. Beauv.), uma gramínea exótica que compromete a recuperação de áreas degradadas em unidades de conservação. Revista Árvore, v.28, n.5, p.739-747, 2004a.

MARTINS, C. R. et al. Monitoramento e controle da gramínea invasora Melinis minutiflora (capimgordura) no Parque Nacional de Brasília, Distrito Federal. In: CONGRESSO BRASILEIRO DE UNIDADES DE CONSERVAÇÃO, 4., 2004,

Curitiba. Seminário 2. Curitiba: Fundação O Boticário de Proteção à Natureza: Rede Nacional Pró Unidade de Conservação. 2004b. p.85-96.

MARTINS, C. R. Caracterização e manejo da gramínea Melinis minutiflora $P$. Beauv. (capim-gordura): uma espécie invasora do cerrado. 2006. 145f. Tese (Doutorado em Ecologia) - Universidade de Brasília, Brasília, 2006.

MASCHIETTO, J. C. Problemas na produção de sementes de capim-colonião. Revista Brasileira de Sementes, v.3, n.1, p.117-121, 1981 .

MITIDIERI, J. Manual de gramíneas e leguminosas para pastos tropicais. São Paulo: Nobel/ Universidade de São Paulo, 1983.
MOHLER, C. L.; GALFORD, A. E. Weed seedling emergence and seed survival: separating the effects of seed position and soil modification by tillage. Weed Research, v.37, NUMERO, p.147-155, 1977.

PANETTA, F. D.; TIMMINS, S. M. Evaluating the feasibility of eradication for terrestrial weed incursions. Plant Protection Quarterly, v.19, n.1, p.5-11, 2004.

PIVELLO, V. R. et al. Abundance and distribution of native and alien grasses in a "cerrado" (Brazilian savanna) biological reserve. Biotropica, v.31, n.1, p.1-82, 1999a.

PIVELLO, V. R.; SHIDA, C. N.; MEIRELLES, S. T. Alien grasses in Brazilian savanas: a treat to the biodiversity. Biodiversity and

Conservation, v.8, n.9, p.1281-1294, 1999b.

RIBEIRO, J. F.; WALTER, B. T. Fitofisionomias do Bioma Cerrado. In: SANO, S.M.; ALMEIDAS, S.P. (Eds.). Cerrado: ambiente e flora. Planaltina: Embrapa-CPAC, 1998. p.89-152.

ROCHA, G. L. et al. Estudo da variação do teor germinativo de sementes de capim-gordura (Melinis minutiflora) armazenadas a baixas temperaturas e em ambiente normal. In: CONGRESSO INTERNACIONAL DE PASTAGENS, 1965, São Paulo. Anais... São Paulo: Secretaria da Agricultura, 1965. v.1. p.531-534.

SKERMAN, P. J.; RIVERS, F. R. Gramineas tropicales. Roma: FAO, 1992. 849p. (Coleción FAO: Producción y Protección Vegetal, 23). 